\title{
KAJIAN KELISTRIKAN PLASMA PIJAR KORONA MENGGUNAKAN ELEKTRODA MULTI TITIK-BIDANG DALAM PERLAKUAN TEKSTIL
}

\section{ELECTRICAL STUDY OF CORONA GLOW DISCHARGE PLASMA USING MULTI POINT TO PLANE ELECTRODES IN TEXTILE TREATMENT}

\author{
Ade Ika Susan ${ }^{1}$, Achmad Sjaifudin T., ${ }^{2}$, Mohamad Widodo ${ }^{3}$, Muhammad Nur ${ }^{1,4}$ \\ ${ }^{1}$ Magister Ilmu Fisika Departemen Fisika, Fakultas Sains dan Matematika, Universitas Diponegoro, Semarang \\ E-mail: adeika.susan@st.fisika.undip.ac.id \\ ${ }^{2}$ Balai Besar Tekstil, Jalan Jenderal Ahmad Yani No. 390 Bandung \\ E-mail: texirdti@bdg.centrin.net.id \\ ${ }^{3}$ Jurusan Kimia Tekstil, Politeknik STTT Bandung, Bandung \\ E-mail: mwidodo@stttekstil.ac.id \\ ${ }^{4}$ Center for Plasma Research, Diponegoro University, Semarang \\ E-mail: m.nur@undip.ac.id
}

Tanggal diterima: 30 Juni 2016, direvisi: 2 November 2016, disetujui terbit: 3 November 2016

\begin{abstract}
ABSTRAK
Studi awal karakteristik arus listrik sebagai fungsi tegangan pada daerah plasma pijar korona untuk perlakuan bahan tekstil telah dilakukan menggunakan reaktor plasma berkonfigurasi multi-titik bidang. Penelitian dilakukan dengan membandingkan karakteristik arus-tegangan pada reaktor plasma pijar korona tanpa dan dengan bahan kain tekstil. Selain itu, penelitian ini juga mengkaji karakteristik arus-tegangan dengan metode input tegangan naik dan tegangan turun. Plasma pijar korona dibangkitkan di antara dua elektroda berkonfigurasi multi-titik bidang menggunakan pembangkit tegangan tinggi DC. Elektroda titik yang digunakan berukuran $(5,6 \mathrm{x} 4,9) \mathrm{cm}^{2}$ dan elektroda bidang berukuran $(12 \times 12) \mathrm{cm}^{2}$ sedangkan kain yang digunakan berukuran $(7 \times 7) \mathrm{cm}^{2}$. Variasi jarak antara elektroda titik dan bidang adalah $1 \mathrm{~cm}, 2 \mathrm{~cm}, 3 \mathrm{~cm}$, dan $4 \mathrm{~cm}$. Tegangan yang digunakan berkisar antara $0-4$ $\mathrm{kV}$ dengan pengamatan nilai arus setiap kenaikan $0,2 \mathrm{kV}$. Hasil penelitian menunjukkan bahwa arus cenderung lebih rendah dengan adanya bahan kain tekstil pada rangkaian multi titik-bidang. Nilai arus tertinggi diperoleh pada jarak elektroda $1 \mathrm{~cm}$ tanpa kain yaitu sebesar 333,33 $\mu \mathrm{A}$ pada tegangan $1,8 \mathrm{kV}$ dibandingkan dengan adanya kain pada jarak dan tegangan yang sama diperoleh nilai arus sebesar $250 \mu \mathrm{A}$. Sedangkan nilai arus terendah diperoleh pada jarak elektroda $4 \mathrm{~cm}$ dengan kain yaitu sebesar $50 \mu \mathrm{A}$ pada tegangan $3,8 \mathrm{kV}$.
\end{abstract}

Kata kunci: Plasmakorona, multi titik-bidang, perlakuan tekstil, input tegangan naik, input tegangan turun.

\section{ABSTRACT}

Characteristic of electrical current as function of voltage on corona glow discharge plasma regions for textile treatment has been carried out. The current of increased and decreasedinput voltages were investigated as well. Some experiments were performed without and with textile fabric (polyester) to investigate those characters. A high voltage DC power has been used to generate plasma between two electrodes in aplasma reactor. This reactor consists of multi-point $(+)$ and plane (- configuration electrodes. The sizes of those electrodes are $(5.6 x$ 4.9) $\mathrm{cm}^{2}$ and $(12 \times 12) \mathrm{cm}^{2}$ for multi-point and plane respectively. The fabrics sizes are about $(7 \times 7) \mathrm{cm}^{2}$.Observations were depended on the distance between the electrodes, i.e. $1,2,3$ and $4 \mathrm{~cm}$. Then, the voltage ranging from 0-4 kV was applied to observe electrical current for each increment of $0.2 \mathrm{kV}$. The experiment with fabric result a lower current than without fabric. The highest current value is $333.33 \mu \mathrm{A}$ at $1.8 \mathrm{kV}$ obtained for $1 \mathrm{~cm}$ electrodes distance and without fabric instead of $250 \mu \mathrm{A}$ with fabric. While the lowest current is $50 \mu \mathrm{A}$ at $3.8 \mathrm{kV}$ obtained for $4 \mathrm{~cm}$ with fabric.

Keywords: Corona glow discharge plasma, multi-point to plane electrode, increasedinput voltage, decreasedinput voltage.

\section{PENDAHULUAN}

Teknologi plasma telah umum digunakan dalam pemrosesan bahan tekstil di industri tekstil dunia. Dari sudut pandang pelestarian lingkungan, teknologi ini berpotensi besar untuk diaplikasikan dalam proses akhir penyempurnaan tekstil karena 
sifat efisiensi energinya dan tidak menghasilkan limbah secara nyata. ${ }^{1}$ Plasma non termal (atau plasma dingin) secara khusus menjadi teknologi yang paling sesuai untuk diaplikasikan dalam pemrosesan kain tekstil karena sebagian besar material tekstil merupakan polimer yang sensitif terhadap panas. ${ }^{2}$ Selain itu, plasma dingin memungkinkan modifikasi permukaan pada seratserat kain tanpa memengaruhi sifat-sifat bulk. ${ }^{3}$ Plasma korona merupakan salah satu bentuk plasma dingin yang cukup umum digunakan dalam pemrosesan bahan tekstil selain plasma jet dan DBD. $^{4}$

Lucutan korona telah dibuktikan merupakan suatu metode yang berguna untuk meningkatkan sifat hidrofilik permukaan polimer, terutama dalam meningkatkan kekuatan material komposit. Weilin Xu dan Xin Liu pada 2003 melaporkan penggunaan lucutan korona untuk modifikasi permukaan polyester. ${ }^{5}$

Plasma pijar korona dalam kondisi atmosfer menjadi suatu metode paling sederhana untuk melakukan modifikasi permukaan kain tekstil, terutama untuk meningkatkan sifat hidrofilik dari kain poliester. ${ }^{6}$ Permasalahan yang muncul adalah belum diketahuinya karakteristik faktor-faktor peradiasian yang optimum dengan menggunakan plasma korona untuk mendapatkan perubahan sifat fisik yang diinginkan dari kain tekstil, sehingga dimungkinkan untuk diterapkan dalam industri tekstil secara nyata.

Penelitian ini mengkaji efek keberadaan sampel kain tekstil pada karakteristik arus terhadap tegangan yang diberikan dalam rangkaian reaktor plasma pijar korona untuk perlakuan bahan tekstil.

\section{Plasma Lucutan Pijar Korona}

Lucutan korona termasuk lucutan mandiri (self-sustained) yang merupakan proses pembangkitan arus di dalam fluida netral diantara dua elektroda bertegangan tinggi dengan mengionisasi fluida tersebut sehingga membentuk plasma di sekitar salah satu elektroda dan menggunakan ion yang dihasilkan dalam proses tersebut sebagai pembawa muatan menuju elektroda lainnya. ${ }^{7}$ Lucutan pijar korona dimulai ketika medan listrik di sekitar elektroda dengan bentuk geometri sangat lengkung (elektroda aktif) memiliki kemampuan untuk mengionisasi spesies gas. ${ }^{\mathbf{8}}$

Suatu korona akan bersifat positif atau negatif bergantung kepada pemberian polaritas tegangan elektroda aktif. Korona positif terjadi ketika elektroda aktif (elektroda dimana proses ionisasi terjadi) dihubungkan dengan terminal positif sumber tegangan. Sedangkan korona negatif terjadi ketika elektroda aktif dihubungkan dengan terminal negatif sumber tegangan. Pada gambar 1, ditunjukkan daerah dalam lucutan pijar korona antara dua elektroda dengan konfigurasi geometri hiperboloid-bidang yang merupakan pendekatan terhadap geometri multi titik-bidang. Pada gambar 1 tersebut terdapat arus yang keluar dari geometri lengkung titik bidang yang dinamakan arus saturasi unipolar korona yang dihasilkan dari ion-ion yang mengalir melalui daerah aliran muatan (drift region).

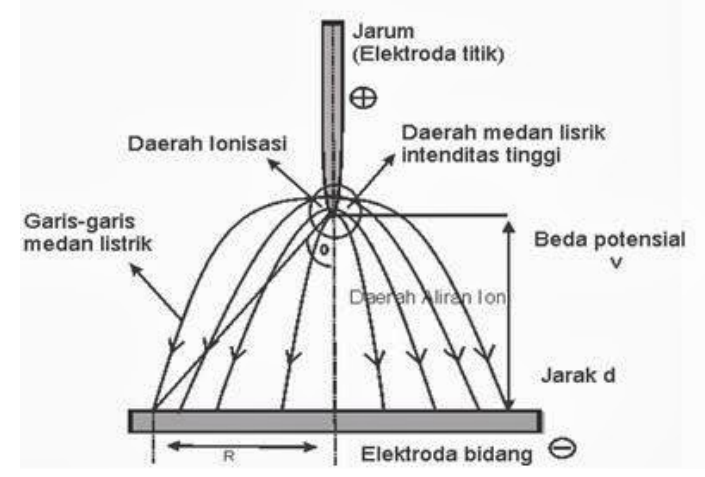

Gambar 1. Ilustrasi daerah antara dua elektroda. Pada lucutan korona titik bidang dengan polaritas positif pada elektroda titik. ${ }^{8}$

Pada konfigurasi elektroda geometri hiperboloid-bidang (pendekatan untuk konfigurasi multi titik-bidang), arus saturasi unipolar korona diberikan oleh persamaan:

$$
I_{S}=\frac{2 \mu \varepsilon_{0} V^{2}}{d},
$$

Dengan $I_{s}$ adalah arus saturasi unipolar korona, $V$ adalah tegangan korona, $\mu$ adalah mobilitas ion unipolar, $\xi_{0}$ adalah permitivitas ruang hampa, dan $d$ adalah jarak antar elektroda. ${ }^{8}$

\section{Plasma Pijar Korona dalam Perlakuan Tekstil}

Dalam penggunaan plasma korona untuk perlakuan pada permukaan, kecepatan transfer spesies-spesies plasma aktif ditentukan dengan mengatur jarak antara substrat dan elektroda. Sistem ini berbasis pada sistem DBD. Frekuensi dari medan listrik pada pembangkit plasma korona untuk perlakuan bahan tekstil berada dalam rentang $10-40 \mathrm{kHz}$; dan medan listrik cukup tinggi, sedangkan potensial yang digunakan dalam orde beberapa kilovolt. Kekurangan utama dari sistem ini adalah bahwa substrat yang akan diradiasi harus melewati ruang antara elektroda dan elektroda lawan. Hal ini berarti bahwa substrat melewati medan listrik dan, dengan demikian, arus lucutan listrik melewati permukaan sementara substrat diradiasi. Dalam beberapa kasus, hal ini dapat menyebabkan kerusakan atau cacat pada substrat. Terutama substrat-substrat poros dengan densitas yang bervariasi sangat rawan terkena efek ini. 
Sistem korona standar dalam industri tekstil terdiri dari elektroda-elektroda pisau logam murni di atas elektroda counter, yang umumnya berupa roller yang menjalankan substrat. ${ }^{10}$ Lucutan korona telah dibuktikan merupakan suatu metode yang berguna untuk meningkatkan sifat hidrofilik permukaan polimer, terutama dalam meningkatkan kekuatan material komposit. ${ }^{11}$

\section{METODE}

Skema dan peralatan yang digunakan dalam penelitian ini ditunjukkan oleh Gambar 1 . Reaktor plasma pijar korona yang digunakan dalam penelitian ini adalah reaktor dengan elektroda berkonfigurasi multi titik-bidang. Elektroda titik yang digunakan berupa jarum berujung runcing dengan diameter $1 \mathrm{~mm}$ dan berjumlah 72 yang dipasang pada suatu PCB. Elektroda bidang berupa pelat logam dari bahan stainless steel. Elektroda titik digunakan sebagai elektroda positif (anoda) dan dan dipasang tegak lurus tehadap elektroda bidang sebagai elektroda negatif (katoda). Jarak antara dua elektroda titik sebesar $0,7 \mathrm{~cm}$. Variasi jarak antara elektroda titik dan bidang adalah $1 \mathrm{~cm}$, $2 \mathrm{~cm}, 3 \mathrm{~cm}$, dan $4 \mathrm{~cm}$.

Bahan kain tekstil berupa kain poliester berukuran $(7 \times 7) \mathrm{cm}^{2}$, ketebalan $0,12 \mathrm{~mm}$, digunakan sebagai sampel diletakkan di atas elektroda bidang. Bahan kain yang dipilih merupakan grey textile.

Plasma pijar korona dibangkitkan menggunakan sumber tegangan tinggi DC (0-4) kV dengan pengamatan nilai arus setiap kenaikan 0,2 $\mathrm{kV}$. Arus listrik dalam rangkaian reaktor plasma tersebut diukur menggunakan multimeter (Sanwa Japan YX360TRF), sedangkan nilai tegangan yang dihasilkan oleh sumber tegangan tinggi (HV) DC diukur menggunakan osiloskop yang dihubungkan dengan probe tegangan tinggi (HV Probe DC max Voltage DC $40 \mathrm{kV}$, AC $28 \mathrm{kV}$ nomor kode EC 1010, EnG1010, Made in Taiwan) untuk mengonversi tegangan dari orde kilo menjadi volt agar tegangan yang masuk dapat terbaca oleh osiloskop. Penelitian ini dilakukan pada tekanan atmosfer dengan suhu ruangan $(26-28)^{\circ} \mathrm{C}$.

Sumber tegangan tinggi DC positif dihubungkan HV probe yang kemudian dihubungkan dengan elektroda titik. Keluaran sumber tegangan tinggi DC negatif dihubungkan dengan elektroda bidang dan HV probe. HV probe dihubungkan dengan osiloskop. Gambar skema peralatan penelitian dapat dilihat pada Gambar 2.

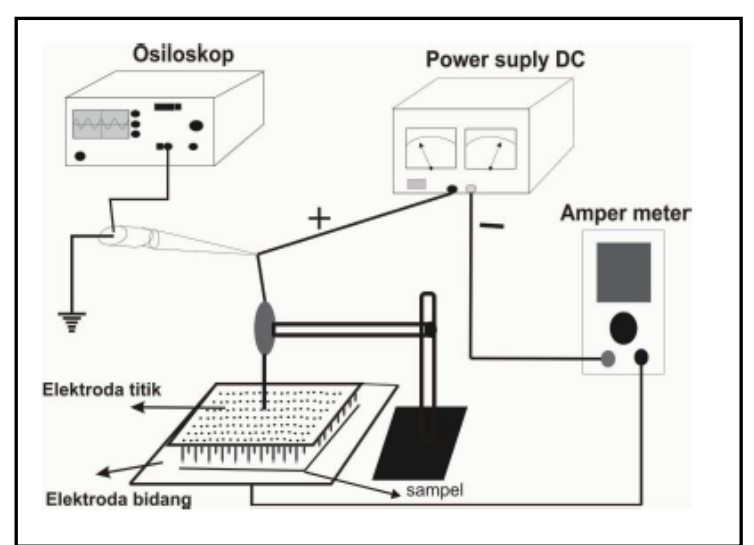

Gambar 2. Skema peralatan penelitian

Karakteristik arus listrik I sebagai fungsi tegangan $\mathrm{V}$ diamati tanpa dan dengan adanya sampel kain tekstil. Selain itu, pengamatan juga dilakukan dengan pemberian input tegangan naik dan tegangan turun.

\section{HASIL DAN PEMBAHASAN \\ Analisis I - V Input Naik dan Turun}

Gambar 3 menunjukkan karakteristik arustegangan (I-V) dengan input tegangan naik dan turun tanpa sampel kain. Berdasarkan grafik tersebut, karakteristik arus listrik sebagai fungsi tegangan cenderung sama, baik pada pemberian tegangan naik maupun turun. Nilai yang sama tersebut menyebabkan penumpukan kurva untuk tegangan naik dan turun, untuk masing-masing jarak antar elektroda $d$. Hal ini berlaku pada semua variasi jarak antar elektroda yang digunakan dalam penelitian ini.

Grafik yang diperoleh berdasarkan hasil penelitian ini sesuai dengan persamaan arus unipolar (Persamaan 1), dimana arus $(I)$ berbanding terbalik dengan jarak antar elektroda $(d)$. Gambar 3 dan 4 menunjukkan bahwa pada tegangan $(V)$ yang sama, semakin besar jarak antar elektroda (d) diperoleh arus $(I)$ yang semakin kecil. Selain itu, Kurva arus-tegangan yang diperoleh juga menunjukkan kurva polinomial orde-2, yang sesuai dengan persamaan 1 dimana nilai arus $(I)$ sebanding dengan kuadrat dari tegangan $\left(V^{2}\right)$. Namun terdapat sangat sedikit perbedaan yang cukup sering muncul pada rentang tegangan 2,0-3,6 kV khususnya pada rangkaian tanpa sampel kain. Misalnya, pada jarak $d=2 \mathrm{~cm}$ tanpa kain terjadi perbedaan nilai arus pada tegangan $2,2 \mathrm{kV}$, dan perbedaan pada tegangan 2,0 - 2,2 kV dengan kain. Pada jarak $\mathrm{d}=3 \mathrm{~cm}$, perbedaan arus terukur pada tegangan $2,6-2,8 \mathrm{kV}$ tanpa kain. Pada jarak $\mathrm{d}=4 \mathrm{~cm}$, perbedaan arus terukur pada tegangan $2,4-3,6 \mathrm{kV}$ tanpa kain, dan $2,2 \mathrm{kV}$ dan 3,6 kV dengan kain. 


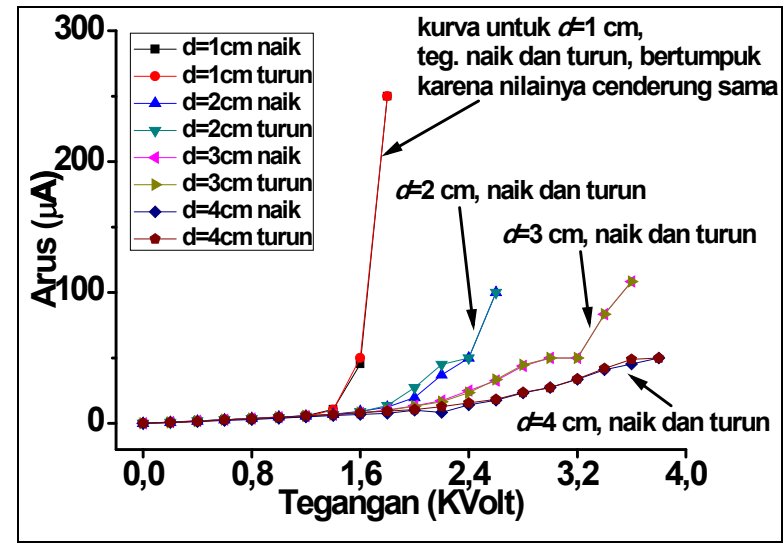

Gambar 3. Grafik karakteristik tanpa sampel kain. Pada pembangkit plasma korona multi titik-bidang, dengan input tegangan naik dan turun.

Perbedaan nilai arus tersebut lebih sering muncul pada daerah mulai munculnya plasma pijar korona yang berada diantara kondisi lucutan Townsend hingga daerah transisi menuju lucutan mandiri, ${ }^{8}$ sehingga kondisi fluktuatif ini berpotensi memberikan perbedaan nilai arus listrik.

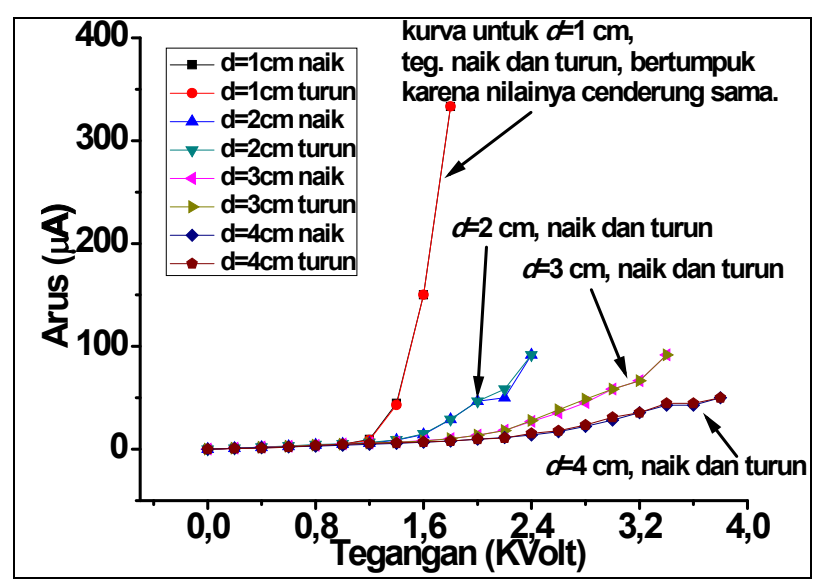

Gambar4. Grafik karakteristik dengan sampel kain. Tegangan-arus pada pembangkit plasma korona multi titik-bidang, dengan input tegangan naik dan turun.

Kecenderungan lainnya yang muncul adalah bahwa arus pada input tegangan turun cenderung lebih rendah dibandingkan dengan saat input tegangan naik. Hal ini menunjukkan bahwa saat tegangan dinaikkan maka ion-ion positif lebih banyak terbentuk dan bergerak menuju kutub negatif (elektroda bidang) sehingga menimbulkan arus yang lebih besar.

Sedangkan saat tegangan diturunkan secara tiba-tiba dari kondisi tegangan tinggi dan arus tinggi akan menyebabkan terjadinya pembalikan kondisi dari lucutan mandiri menuju kondisi dadal sehingga menyebabkan perbedaan nilai arus, yang cenderung lebih rendah, dibandingkan kondisi saat pemberian tegangan naik.

Pada perlakuan tanpa adanya sampel kain lebih sering memunculkan perbedaan nilai arus dibandingkan dengan saat adanya sampel kain, hal ini berhubungan dengan adanya perbedaan nilai arus pada perlakuan tanpa dan dengan sampel kain, dimana pada saat adanya kain nilai arus yang diperoleh lebih kecil dibandingkan dengan saat tanpa sampel kain.

Kesesuaian hasil penelitian dengan persamaan arus saturasi unipolar ditunjukkan dalam Gambar 5, yaitu nilai arus (I) sebanding dengan kuadrat tegangan $\left(V^{2}\right)$ yang ditunjukkan melalui kurva polinomial orde dua. Hasil plot grafik ini selanjutnya dapat digunakan untuk menentukan mobilitas pembawa muatan yang bergerak di dalam medan listrik dalam rangkaian reaktor plasma multi titik-bidang.

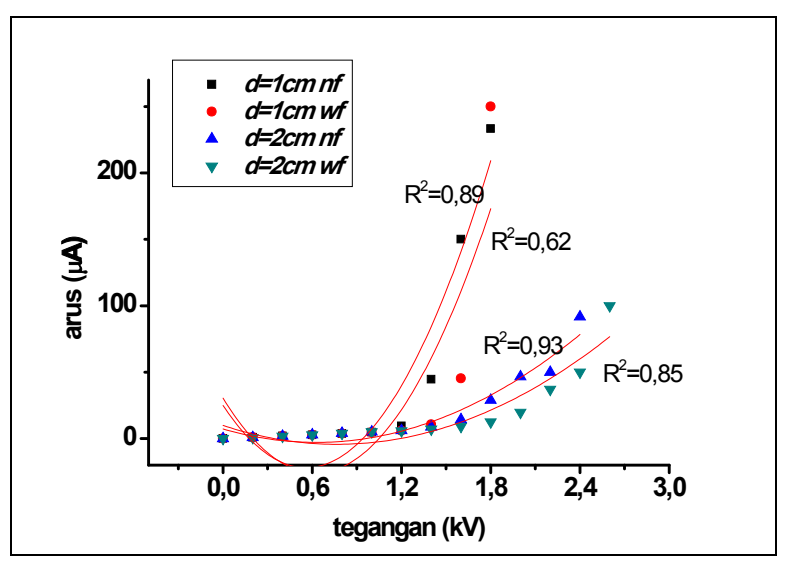

Gambar 5. Grafik kesesuaian hasil penelitian dengan plot kurva polinomialnya.

\section{Analisis I-V Tanpa dan Dengan Sampel Kain}

Karakteristik arus listrik $I$ sebagai fungsi tegangan $V$ yang dilakukan menggunakan input tegangan naik adanya perbedaan nilai antara perlakuan tanpa dan dengan adanya sampel kain. Nilai arus dengan adanya sampel kain cenderung lebih tinggi dibandingkan dengan adanya sampel kain, seperti ditunjukkan pada Gambar 6. Pola ini terjadi pada semua variasi jarak $d$ yang digunakan dalam penelitian ini.

Gambar 6 menunjukkan arus listrik rerata yang terjadi sebagai fungsi tegangan untuk lucutan dengan sampel kain dan tanpa sampel kain. Dari grafik yang disajikan pada Gambar 6 (grafik semilog), terlihat dengan jelas terdapat transisi. Daerah transisi tersebut diperoleh pada tegangan sekitar 1,2 kV dan arus 6-8 mikro Ampere. Transisi ini disebut transisi antara lucutan Townsend (arus masih sangat rendah), dengan lucutan korona (arus naik secara tajam). Arus listrik yang terjadi pada lucutan gas merupakan arus kapasitif. Muatan yang bergerak ini diawali oleh peristiwa ionisasi di 
sekitar elektroda titik. Ionisasi terjadi di sekitar elektroda titik, karena pengaruh medan listrik dengan intensitas tinggi. Ion-ion hasil ionisasi pada zona ionisasi (zona plasma) akan mengalir atau bergerak menuju katoda melalui daerah aliran (drift region). Aliran ion-ion ini akan menimbulkan arus ion yang disebut arus saturasi unipolar. Aliran ion sering disebut angin ion ini akan membawa juga molekul dan atom gas yang berada diantara kedua elektroda dan dikenal dengan elektrohidrodinamik (EHD). ${ }^{8,12,13}$

EHD ini juga mengandung Reactive Oxygen Species (ROS) yang disinyalir dapat mengubah sifat permukaan kain. ${ }^{10}$ Sedangkan pada perlakuan dengan adanya sampel kain, ion-ion positif hasil ionisasi akan menuju kain. Setelah terjadi penangkapan elektron oleh ion maka atom atau molekul tersebut akan kembali menjadi atom atau molekul netral. Di dalam plasma peristiwa ionisasi dan rekombinasi berlangsung dalam waktu yang sangat singkat dan bersamaan. Dengan perkataan lain bahwa di dalam plasma khususnya plasma non-termik selalu terjadi suatu atom atau molekul akan kehilangan elektronnya dan sebaliknya di sisi lain juga ada ion-ion yang menangkap elektron sehingga berubah menjadi atom atau molekul netral. ${ }^{14,15}$

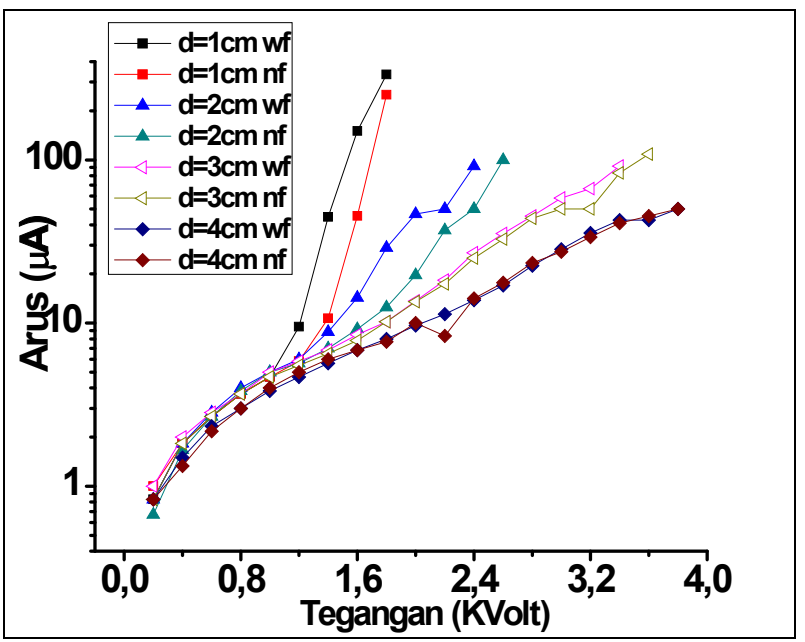

Gambar 6. Gabungan hasil karakterisasi arustegangan dengan dan tanpa kain. Variasi jarak antar elektroda $d=1 \mathrm{~cm}$, $d=2 \mathrm{~cm}, d=3 \mathrm{~cm}, d=4 \mathrm{~cm}$.

Selain itu, faktor lain yang mempengaruhi nilai arus pada rangkaian adalah jarak efektif antar setiap elektroda titik serta jarak antara elektroda titik dan bidang. Dalam penelitian sebelumnya, Nur dkk. 2014, melakukan karakterisasi sudut arah angin ion pada plasma korona, diperoleh bahwa nilai maksimum adalah pada sudut dari $59^{\circ}$ sampai $65^{\circ}$ terhadap garis tegak lurus antara kedua elektroda. ${ }^{12}$ Hal tersebut menunjukkan bahwa pada masing-masing jarak $d$, terdapat daerah yang terkena dua imbas medan dari dua elektroda titik, semakin besar $d$ maka semakin besar daerah terimbas medan ganda. Hal ini menyebabkan adanya interaksi antar ion-ion positif sehingga berdampak pada semakin rendahnya nilai arus yang terukur. Semakin besar jarak $d$ maka semakin kecil nilai arus yang terukur.

\section{KESIMPULAN}

Berdasarkan hasil penelitian dan pembahasan yang telah dilakukan, maka dapat ditarik kesimpulan sebagai berikut:

- Arus pada input tegangan turun cenderung lebih rendah dibandingkan dengan saat input tegangan naik.

- Perbedaan nilai arus pada input tegangan naik dan turun tersebut lebih sering muncul pada daerah transisi antara lucutan Townsend dangan lucutan pijar korona.

- Nilai arus dengan adanya sampel kain cenderung lebih tinggi dibandingkan dengan tanpa sampel kain.

- Semakin besar jarak elektroda titik dan bidang $d$ maka semakin kecil nilai arus yang terukur. Dari kajian kelistrikan ini dan terhadapnya terindikasinya terjadi EHD yang membawa Reactive Oxygen Species (ROS).

Penelitian yang lebih intensif masih diperlukan untuk mempelajari ROS yang dihasilkan lucutan korona secara kuantitatif melalui kajian kimia dan spektroskopi.

\section{Ucapan Terima Kasih}

Penulis utama mengucapkan terimakasih kepada Center for Plasma Research (CPR), Balai Besar Tekstil-Bandung, dan Politeknik Sekolah Tinggi Teknologi Tekstil - Bandung atas kesempatan dan dukungan untuk melakukan penelitian ini.

\section{PUSTAKA}

${ }^{1}$ Gotoh K. dan Yasukawa A., (2010). Atmospheric pressure plasma modification of polyester fabric for improvement of textile-specific properties. Textile Research Journal, 8 (4): 368-378.

${ }^{2}$ Morent R., De Geyter N., Verschuren J., De Clerck K., Kiekens P., dan Leys C., (2008). Non-thermal plasma treatment of textiles, Surface \& Coatings Technology, 202:34273449.

${ }^{3}$ Gouanve F., Meyer M., Grenet J., Marais S., Poncin E.F., dan Saiter J.-M., (2006). Unsaturated poliester resin (UPR) reinforced 
with flax fibers, untreated and cold $\mathrm{He}$ plasma-treated: thermal, mechanical and DMA studies, Composite Interfaces, 13(4-6): 355-364.

${ }^{4}$ Buyle, G., Rogister Y., Lefranc O., dan Paul A., (2008). Anti microbial coatings on textile fabrics via continous atmospheric plasma deposition. Proceedings of the 8th AUTEX Conference, 24-26.

${ }^{5}$ Weilin X.dan Xin L., (2003). Surface modification of poliester fabric by corona discharge irradiation. European Polymer Journal, 39: 199-202.

${ }^{6}$ Shishoo, R. (Ed.), (2007). Plasma Technology for Textiles. Woodhead Publishing, Ltd, Cambridge.

${ }^{7}$ Chen, J., dan Davidson, J.H., (2002). Electron Density and Energy Distributions in the Positive DC Corona: Interpretation for Corona-Enchaned Chemical Reaction. Plasma Chemistry and Plasma Processing, 22, 199-224.

${ }^{8}$ M. Nur, M., Bonifaci, N.,dan Denat, A., (2014). Ionic Wind Phenomenon and Charge Carrier Mobility in Very High Density Argon Corona Discharge Plasma.Journal of Physics Conference Series, 495 (2014): 012041.

${ }^{9}$ Nur, M., (2011). Fisika Plasma dan Aplikasinya. Book 1st Edition, Undip Press, Semarang.
${ }^{10}$ Buyle, G., (2007). Plasma coating on textile materials. Plasma Technology for Hyperfunctional Surface, 21-22.

${ }^{11}$ Samu R., Moulee A., dan Kumar V.G., (1999). Effect of charge and hydrophobicity on adsorption of modified starches on polyester, J. Colloid Interface Sci, 220: 260-268.

${ }^{12}$ Nur M., Azzulkha A.H., Restiwijaya M., Muchlisin Z., dan Sumariyah, (2014). The Study of Electrohydrodynamic and Wind Ions Direction Produced by Positive Corona Plasma Discharge. Advances in Physics Theorities and Application. 30.

${ }^{13}$ Sumariyah, Kusminarto, Hermanto A., Nuswantoro P., Muhlisin Z.,dan Evi S., (2015). Modeling of Electric Potential Distribution in EHD Flow Zone Utilizing Pin-Multi Ring Consentric Electrodes. Procedia Environmental Sciences, 23: 260.

${ }^{14}$ Susan A.I., (2016). Kajian Perubahan Sifat Pembasahan Kain Poliester dan Kapas Akibat Radiasi Plasma Lucutan Pijar Korona.Thesis magister Ilmu Fisika, Undip.

${ }^{15}$ Nasser E., (1971). Fundamental of Gasseous Ionization and Plasma Electronics. WileyInterscience, New York. 